\begin{tabular}{l|l|l|l}
$\begin{array}{c}\text { Case Reports in } \\
\text { Demiliatology }\end{array}$ & $\begin{array}{l}\text { Case Rep Dermatol 2010;2:156-164 } \\
\text { DOI: } 10.1159 / 000320207\end{array}$ & $\begin{array}{l}\text { Published online: } \\
\text { August 27, 2010 }\end{array}$ & $\begin{array}{l}\text { I 2010 S. Karger AG, Basel } \\
\text { ISSN 1662-6567 } \\
\text { www.karger.com/cde }\end{array}$ \\
\hline
\end{tabular}

\title{
Vitiligo at Injection Site of PEG-IFN-a 2a in Two Patients with Chronic Hepatitis C: Case Report and Literature Review
}

\author{
V. Arya M. Bansal L. Girard S. Arya A. Valluri
}

Wyckoff Heights Medical Center, Brooklyn, N.Y., USA

\section{Key Words}

Vitiligo $\cdot$ Injection site $\cdot$ PEG-IFN-a 2a $\cdot$ Chronic hepatitis C

\begin{abstract}
A 72-year-old female and a 57-year-old male with chronic hepatitis $C$ were treated with a combination therapy of pegylated interferon (PEG-IFN)-a 2a (180 $\mu$ g s.c. once a week) and ribavirin $(1,000 \mathrm{mg}$ orally daily). This resulted in the destruction of melanocytes at the injection site in both patients. In the male patient, the depigmentation progressed to the surrounding skin area. The dermatologist concurred with vitiligo as the diagnosis in both patients. Injection and surrounding site vitiligo associated with PEG-IFN-a 2b treatment for hepatitis $C$ was noticed in previous case studies. For the first time, the case reports below highlight the same immunological adverse event secondary to PEG IFN-a $2 \mathrm{a} /$ ribavirin combination therapy and explain, in part, the complex interaction between host immune response and viral genotype. In addition, we systematically review drug-induced vitiligo and autoimmune diseases associated with the depigmentation disorder.
\end{abstract}

\section{Introduction}

Hepatitis C virus (HCV) is second only to non-alcoholic steatohepatitis (NASH) as the most common cause of chronic hepatitis [1]. Since 2001, the most widely accepted viral clearance therapy is pegylated interferon (PEG-IFN)- $\alpha 2 b / 2 a$ in combination with ribavirin. Adverse effects of this combination therapy are variable and mainly include flu-like illness, neuropsychiatric symptoms such as depression, and thyroid, dermatological and hematological abnormalities. Existing literature attributes all major side effects of the combination therapy to PEG-IFN except hemolytic anemia, which is a side effect of ribavirin [2]. Patients should be monitored for further evaluation of additional adverse effects of PEG-IFN. 


\begin{tabular}{c|l|l|l}
$\begin{array}{c}\text { Case Reports in } \\
\text { Demillatology }\end{array}$ & $\begin{array}{l}\text { Case Rep Dermatol 2010;2:156-164 } \\
\text { DOI: } 10.1159 / 000320207\end{array}$ & $\begin{array}{l}\text { Published online: } \\
\text { August 27, 2010 }\end{array}$ & $\begin{array}{l}\text { O 2010 S. Karger AG, Basel } \\
\text { ISSN 1662-6567 } \\
\text { www.karger.com/cde }\end{array}$ \\
\hline
\end{tabular}

Few cases of interferon-associated vitiligo have been reported in the past [3-8]. Vitiligo, an idiopathic acquired form of skin disease, is caused by destruction of epidermal melanocytes. The worldwide prevalence is $1-2 \%$, with no race or gender predilection. The presence of serum autoantibodies targeting the surface of melanocytes [9] and of a large number of $\mathrm{T}$ cells specific for melanocyte antigens in vitiligenous lesions [10] suggests an autoimmune etiology; however, the exact pathogenesis remains unclear. PEG-IFN- $a 2 b$ injection site vitiligo has been reported once [8]. However, PEG-IFN- $\alpha$ 2a injection site and surrounding site vitiligo has never been reported; the following case reports highlight this potential treatment-related complication.

\section{Case Presentation}

\section{Case 1}

A 72-year-old Hispanic female was referred for chronic hepatitis C evaluation. Physical examination was normal. She denied any exposure to hepatitis-C-related risk factors. Her laboratory workup was negative except for raised liver enzymes, viral load $\log 5.5$, and genotype 1a. She was started on combination therapy of PEG-IFN-a 2a (Pegasys ${ }^{\circledR}$; Roche Pharmaceuticals, Nutley, N.J., USA) $180 \mu \mathrm{g}$ once a week and ribavirin 1,000 mg daily. Apart from flu-like symptoms after the first few injections, she tolerated the combination therapy well. After 12 weeks of therapy, her HCV RNA was undetectable. During the fourth month of therapy, the patient developed white macular skin lesions around PEG-IFN- $\alpha$ 2a injection sites on both upper arms ( $\underline{\text { fig. }} \mathbf{1} \mathrm{a}, \mathrm{b}$ ). These lesions increased in diameter during therapy and remained the same after discontinuation of therapy. Her HCV RNA (PCR) was undetectable after 48 weeks of treatment, but after 6 months, it returned positive.

Case 2

A 57-year-old Hispanic male was referred (to an internist) for complete workup for hepatitis C. He denied any exposure to hepatitis-C-related risk factors. He had abnormal liver enzyme values, but other laboratory values were within normal limits. His hepatitis $\mathrm{C}$ workup showed genotype $2 \mathrm{~b}$ and viral load $\log 7$. He was started on PEG-IFN-a 2a $180 \mu \mathrm{g}$ weekly and ribavirin $800 \mathrm{mg}$ daily. In the fifth month of therapy, he developed white macular lesions on both thighs around PEG-IFN- $\alpha$ 2a injection sites (

2). The vitiligo spread throughout the whole body except his face. His HCV RNA was undetectable after 12- and 24-week intervals of therapy, and 6 months after discontinuation of therapy.

Both patients agreed to continue with the antiviral treatment. There was no past medical or family history of any autoimmune disorder or especially vitiligo. Autoimmune markers were also negative in both patients. Diagnosis of vitiligo has been confirmed by dermatologist consultation in both cases (table 1).

\section{Discussion}

Understanding the immunological adverse events in chronic hepatitis $C$ is a complex phenomenon. The genotypic variability of the treatment response and host immunological status plays an important role in this complexity [11]. It was observed in the previous case reports that autoimmune manifestations are more common in patients with stronger immune response. Th1 and Th2 cytokine ratio may be a major determinant affecting the outcome of the treatment. The Th2 cytokine profile (IL-4 and IL-10) correlates with the persistence of the disease [12] and less autoimmune manifestations. 


\begin{tabular}{r|l|l|l}
$\begin{array}{c}\text { Case Reports in } \\
\text { Deillatology }\end{array}$ & $\begin{array}{l}\text { Case Rep Dermatol 2010;2:156-164 } \\
\text { DOI: } 10.1159 / 000320207\end{array}$ & $\begin{array}{l}\text { Published online: } \\
\text { August 27, 2010 }\end{array}$ & $\begin{array}{l}\text { O 2010 S. Karger AG, Basel } \\
\text { ISSN 1662-6567 } \\
\text { www.karger.com/cde }\end{array}$ \\
\hline
\end{tabular}

\section{Vitiligo and Interferon}

We reviewed all case reports of vitiligo in hepatitis $C$ patients and realized that vitiligo lesions appeared during the first 6 months of IFN- $\alpha$ or PEG-IFN- $\alpha$ therapy. In a US male veterans' study, a significant relationship between hepatitis $C$ and vitiligo was reported [13], whereas in two other studies, it was shown that the seroprevalence of HCV in vitiligo patients was not significantly different from the controls $[14,15]$. In all these case reports, severity of the vitiligo and virological response achieved were correlated. Sustained virological response (SVR) due to stronger immune response was associated strongly with appearance of more generalized vitiligo lesions. However, a direct association between chronic hepatitis $\mathrm{C}$ and vitiligo is still debatable.

It appears that the time of onset and the course of vitiligo in IFN- $\alpha$ and PEG-IFN- $\alpha$ associated cases is variable. Hamadah et al. [16] reported 8 cases of noninjection site IFNtreatment-related vitiligo in chronic hepatitis $\mathrm{C}$ patients. Autoimmune disease history (Hashimato's thyroiditis and primary hypothyroidism) was noted in 2 out of 8 patients [16]. In one case report, vitiligo vanished completely after cessation of IFN [5] while in others, skin lesions persisted even after a few months of withdrawal of IFN [6] or PEGIFN- $\alpha 2 \mathrm{a}[17]$.

Interestingly, Taffaro et al. [18] reported a chronic hepatitis C patient whose old vitiligo lesions improved after initiation of PEG-IFN- $\alpha 2 a$ and ribavirin therapy. It may be a result of immune modulation by PEG-IFN.

Vitiligo at injection site of IFN- $\alpha 2 b$ has been reported in one case of hepatitis $\mathrm{C}$ who was previously diagnosed with vitiligo capitis [8]. What makes these case reports unique is that vitiligo originated at the injection site of PEG-IFN- $\alpha$ 2a in patients with no past medical history and has diffusely progressed in one patient (table 2).

\section{PEG-IFN as an Etiological Factor for Vitiligo}

The suggested etiopathogenesis behind drug-induced vitiligo is: (1) activation of cytotoxic T cells directed against melanocyte antigens, (2) damage to sympathetic nerves that are connected by chemical synapses to melanocytes with a resultant functional disturbance, and (3) a direct cytotoxic nature of the drug on melanocytes (apoptosis). Most of the mechanisms suggested are hypothetical with no direct or scientific evidence to establish the exact role of the implicated drug.

The mechanism of action of PEG-IFN, a well-known immune-modulator, may provide a clue for its role in the pathogenesis of vitiligo. Current knowledge supports the role of PEG-IFN- $\alpha$ therapy in accelerated lymphocyte attachment to endothelial cells with deposition of immune complexes and vasculitis $[19,20]$. In our patients, we hypothesize that vitiligo at PEG-IFN- $\alpha$ 2a injection site could be due to PEG-IFN-induced cytotoxic $\mathrm{T}$-cell-mediated immune response against melanocytes at the injection site, with a resultant local destruction of melanocytes. It is possible that PEG-IFN- $\alpha$ 2a might have triggered this process in chronic hepatitis $\mathrm{C}$ patients. Its role as a causative factor is also supported by similar findings in patients during the treatment of chronic myeloid leukemia, hepatitis B and C, and malignant melanoma [3-7]. 
Viral genotype and host immune status may explain the localization or the progression of vitiligo in our patients. In the patient with genotype 1a, early virologic response and early treatment response was achieved and maintained for a short span of time. The SVR was not achieved in this patient. We consider the cytokine profile in this strain of patients may be of the Th2 variety. Th2 cells secrete IL-4, IL-5, and IL-10, which help B cells produce neutralizing antibodies. The cytokines shift the body's attack mechanism towards increasing the humoral response while decreasing the cytotoxic component. With the body's immune response focusing on non-self targets, attack on melanocytes is suppressed and progression of vitiligo is prevented after treatment.

In our second patient with genotype $2 \mathrm{~b}, \mathrm{SVR}$ was achieved. We consider the higher Th1 activity in genotype $2 \mathrm{~b}$ is more efficient at removing virally infected cells. Th 1 produces IL-2, which encourages cytotoxic T cells to induce apoptosis in the infected cells, and IFN- $\gamma$, which stimulates macrophages to engulf the virally infected particle. The Th1 cytokines and stronger cell-mediated immune response may be the reason for a more intense form of vitiligo in this patient [21]. Due to its potential to reveal the future course of this adverse event, monitoring cytokines may be considered for research purposes.

\section{PEG-IFN-Related Dermatological Side Effects}

A list of dermatological side effects related to PEG-IFN has been reported which include necrosis, psoriasis, hyperpigmentation and vasculitis at the injection site, xerosis, pruritus, urticaria, and reversible hair loss, sudden onset of psoriasis or flaring of preexisting psoriasis, pityriasis rosea, lichen planus, eosinophilic fasciitis and vitiligo [2].

\section{Drugs Causing Vitiligo}

Drug-induced vitiligo is frequently reported [22-25]; some culprit drugs are listed in table 3. Suggested mechanisms of action in the causation of vitiligo are hypothetical.

\section{Vitiligo and Other Autoimmune Diseases}

Vitiligo is associated with a substantial number of other autoimmune conditions [2639]. In both children and adults, the most common autoimmune disorder known to be associated with non-segmental vitiligo is autoimmune thyroiditis [40, 41]. Skin diseases and malignancies have been reported in association with vitiligo [33-39]. The rare association of segmental subtype of vitiligo with autoimmune diseases further supports its neural etiology [42].

\section{Conclusion}

Vitiligo with chronic hepatitis $\mathrm{C}$ treatment, certain other drug treatment, and its associated autoimmune diseases were briefly reviewed (table 4). PEG-IFN-associated immune modulation explained its autoimmune triggering role in our HCV and vitiligo 
patients. Host immune status provided a clue for the localization or progression of the depigmentation.

PEG-IFN- $\alpha 2$ a demonstrated a significant benefit in the treatment of chronic hepatitis C. Its antiviral benefits and adverse effects are both mediated via the induction of cytokines. In the era of the widespread use of PEG-IFN- $\alpha$ 2a as the treatment for chronic hepatitis $\mathrm{C}$, clinicians should be aware of these diverse pigmentary changes and subsequent disfiguration associated with its use. Furthermore, clinicians should keep in mind that not all individuals treated with PEG-IFN- $\alpha$ 2a will experience melanocyte destruction. More research is indeed needed to explain the rare pathogenesis of injection and surrounding site vitiligo since the course of the dermatological disease is unpredictable.

Table 1. HCV subtype and response upon treatment

\begin{tabular}{lll}
\hline Time line & $\begin{array}{l}\text { Case 1 } \\
(\text { Genotype 1a) }\end{array}$ & $\begin{array}{l}\text { Case 2 } \\
\text { (Genotype 2b) }\end{array}$ \\
\hline 0 weeks & Treatment started & Treatment started \\
12 weeks & VL* - undetectable & VL - undetectable \\
16 weeks & Vitiligo at injection site & NA \\
20 weeks & Vitiligo at injection site & Vitiligo at injection site \\
24 weeks & Vitiligo at injection site & Vitiligo at injection and surrounding site \\
& VL - not reported & VL - undetectable \\
48 weeks & Vitiligo at injection site & Vitiligo at injection and surrounding site \\
& VL - undetectable & VL - not reported \\
6 months & Vitiligo at injection site & More diffuse Vitiligo \\
& VL - detectable & VL - undetectable \\
Host immune response & Weak & Strong \\
\hline
\end{tabular}

* Viral load. 
Table 2. Case reports on PEG-IFN- $\alpha$ related vitiligo

\begin{tabular}{|c|c|c|c|c|}
\hline PEG-IFN & Report & $\begin{array}{l}\text { Past history } \\
\text { of vitiligo }\end{array}$ & $\begin{array}{l}\text { Effect of treatment } \\
\text { discontinuation }\end{array}$ & $\begin{array}{l}\text { History of } \\
\text { autoimmune } \\
\text { disorder }\end{array}$ \\
\hline \multicolumn{5}{|c|}{ Injection site local $^{1}$} \\
\hline $2 \mathrm{a}$ & Present report (case 1) & No & Stable & No \\
\hline $2 \mathrm{~b}$ & Anbar et al., 2008 [8] & Yes & Stable & No \\
\hline \multicolumn{5}{|c|}{ Injection site diffuse ${ }^{2}$} \\
\hline $2 \mathrm{a}$ & Present report (case 2) & No & More diffuse & No \\
\hline $2 \mathrm{~b}$ & Never reported & NA & NA & NA \\
\hline \multicolumn{5}{|c|}{ Generalized vitiligo } \\
\hline \multirow[t]{4}{*}{$2 \mathrm{a}$} & Nouri et al., 1997 [43] & No & More diffuse & No \\
\hline & Krzysztof et al., 2006 [17] & Yes & Stable & No \\
\hline & Seckin et al., 2004 [3] & No & More diffuse & No \\
\hline & Simsek et al., 1996 [5] & No & Regression & No \\
\hline \multirow[t]{2}{*}{$2 b$} & Bernstein et al., 1995 [6] & No & Stable & No \\
\hline & Patricia et al., 2006 [7] & No & Stable & No \\
\hline
\end{tabular}

${ }^{1}$ Local $=$ Injection site vitiligo remained local.

${ }^{2}$ Diffuse $=$ Injection site vitiligo spread to whole body.

Table 3. Drugs causing vitiligo

\begin{tabular}{ll}
\hline Group & Drugs \\
\hline Anticonvulsants & Carbamazepine, valproic acid, clonazepam, phenytoin \\
Antimalarials & Chloroquine, quinine \\
Antiparkinson's drugs & Tolcapone, levodopa \\
Drugs for alopecia & Diphencyprone, squaric acid dibutylester \\
Biological drugs & Interleukin-2, interleukin-4, interferon $\alpha$ and $\beta$, infliximab, imiqimod, imatinib \\
Other drugs & Fluphenazine, clofazimine, dopamine, hydroquinone monobenzylether ester, \\
& ganciclovir, $\beta$-blockers, lispro insulin \\
\hline
\end{tabular}

Table 4. Vitiligo and other autoimmune diseases

\begin{tabular}{ll}
\hline Associations & Case reports \\
\hline Autoimmune thyroiditis & Autoimmune hepatitis \\
Autoimmune gastritis & Primary biliary cirrhosis \\
Alopecia areata & Behçet's disease \\
Diabetes mellitus & Celiac disease \\
Rheumatoid arthritis & Myasthenia gravis \\
Pernicious anemia & Sjögren's syndrome \\
Addison's disease & Autoimmune nephritis \\
Hashimoto's thyroiditis & Pachydermoperiostosis \\
Vogt-Koyanagi-Harada Syndrome & Neurofibromatosis type 1 \\
Loss of hair pigmentation & Hematopoietic cell transplantation \\
Polyglandular autoimmune syndrome & Dermatitis herpetiformis \\
\hline
\end{tabular}




\begin{tabular}{r|l|l|l}
$\begin{array}{c}\text { Case Reports in } \\
\text { Deillatology }\end{array}$ & $\begin{array}{l}\text { Case Rep Dermatol 2010;2:156-164 } \\
\text { DOI: } 10.1159 / 000320207\end{array}$ & $\begin{array}{l}\text { Published online: } \\
\text { August 27, 2010 }\end{array}$ & $\begin{array}{l}\text { O 2010 S. Karger AG, Basel } \\
\text { ISSN 1662-6567 } \\
\text { www.karger.com/cde }\end{array}$ \\
\hline
\end{tabular}

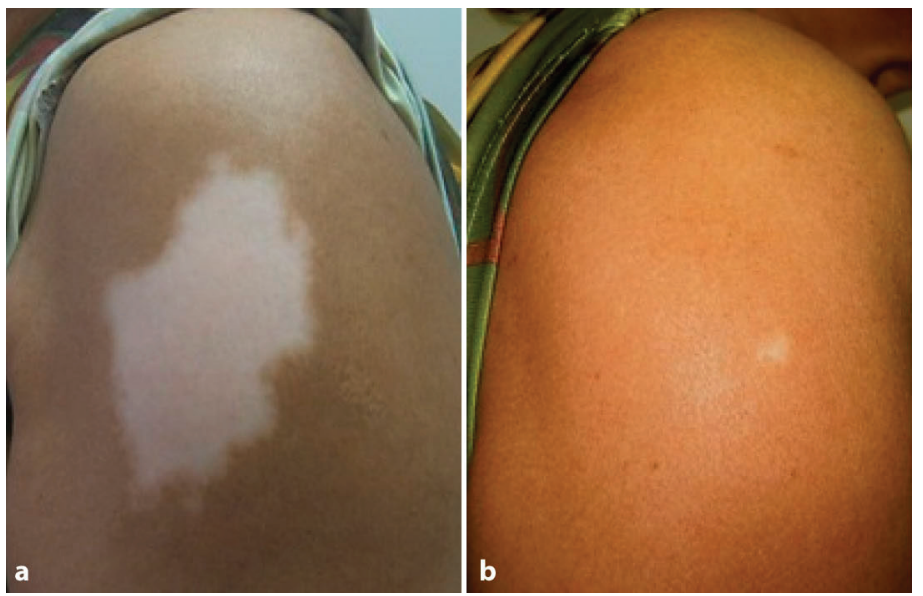

Fig. 1. Localized vitiligo (case 1) at the injection site. a Left arm. b Right arm.

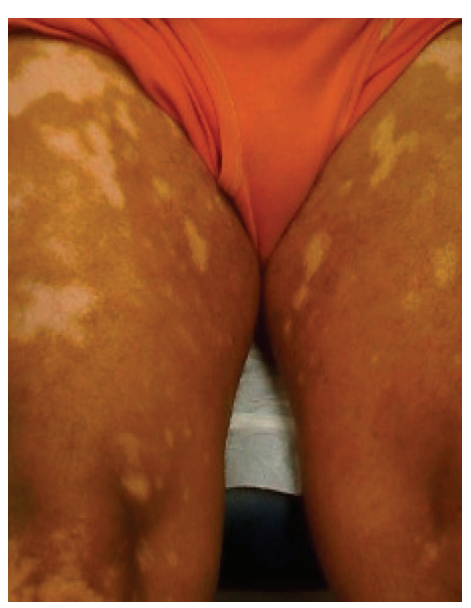

Fig. 2. Generalized vitiligo (case 2 ) on treatment.

\section{References}

1 Wieckowska A, McCullough AJ, Feldstein AE: Noninvasive diagnosis and monitoring of nonalcoholic steatohepatitis: present and future. Hepatology 2007;46:582-589.

2 Russo MW, Fried MW: Side effects of therapy for chronic hepatitis C. Gastroenterology 2003;124:1711-1719.

-3 Seckin D, Durusoy C, Sahin S: Concomitant vitiligo and psoriasis in a patient treated with interferon alfa-2a for chronic hepatitis B infection. Pediatr Dermatol 2004;21:577-579.

4 Guillot B, Blazquez L, Bessis D, Dereure O, Guilhou JJ: A prospective study of cutaneous adverse events induced by low-dose alpha Interferon treatment for malignant melanoma. Dermatology 2004;208:49-54.

5 Simsek H, Savas C, Akkiz H, Telatar H: Interferon-induced vitiligo in a patient with chronic viral hepatitis C infection. Dermatology 1996;193:65-66.

6 Bernstein D, Reddy KR, Jeffers L, Schiff E: Canities and vitiligo complicating interferon therapy for hepatitis C. Am J Gastroenterol 1995;90:1176-1177.

7 Patricia T, Hadi S, Al-Ghaithi K, Al-Qari H, Rudikoff D: Segmental vitiligo and hair curling after interferon alpha and ribavirin treatment for hepatitis C. Skinmed 2006;5:50-51. 
8 Anbar TS, Abdel-Rahman AT, Ahmad HM: Vitiligo occurring at site of interferon-alpha $2 \mathrm{~b}$ injection in a patient with chronic viral hepatitis C: a case report. Clin Exp Dermatol 2008;33:503.

9 Gilhar A, Zelickson B, Ulman Y, et al: In vivo destruction of melanocytes by the IgG fraction of serum from patients with vitiligo. J Invest Dermatol 1995;105:683-686.

10 Van den Wijngaard R, Wankowicz-Kalinska A, Le Poole IC, Tigges B, Westerhof W, Das PK: Local immune response in skin of generalized vitiligo patients: destruction of melanocytes is associated with the prominent presence of CLA+ T cells at the perilesional site. Lab Invest 2000;80:1299-1309.

11 Rossi G, Tucci A, Cariani E, Ravaggi A, Rossini A, Radaeli E: Outbreak of hepatitis C virus infection in patients with hematologic disorders treated with intravenous immunoglobulins: different prognosis according to the immune status. Blood 1997;90:1309-1314.

12 Fan XG, Liu WE, Li CZ, Wang ZC, Luo LX, Tan DM, Hu GL, Zhang Z: Circulating Th1 and Th2 cytokines in patients with hepatitis C virus infection. Mediators Inflamm 1998;7:295-297.

13 El-Serag HB, Hampel H, Yeh C, Rabeneck L: Extrahepatic manifestations of hepatitis C among United States male veterans. Hepatology 2002;36:1439-1445.

14 Jadali Z, Eslami MB, Sanati MH, Mansouri P, Mahmoudi M, Maghsoudi N, et al: Hepatitis C virus antibodies and vitiligo disease. Iranian J Publ Health 2005;34:23-26.

15 Akbayir N, Gökdemir G, Mansur T, Sökmen M, Gündüz S, Alkim C, et al: Is there any relationship between hepatitis C virus and vitiligo? J Clin Gastroenterol 2004;38:815-817.

16 Hamadah I, Binamer Y, Sanai FM, Abdo AA, Alajlan A: Interferon-induced vitiligo in hepatitis C patients: a case series. Int J Dermatol 2010;49:829-833.

17 Krzysztof T, Romana M, Grażyna S: Vitiligo associated with pegylated interferon and ribavirin treatment of patients with chronic hepatitis C: a case report. Adv Ther 2006;23:139-142.

18 Taffaro M, Pyrsopoulos N, Cedron H, Cacayorin E, Weppler D, Moon J, et al: Vitiligo improvement in a hepatitis $C$ patient after treatment with PEG-interferon alpha-2a and ribavirin: a case report. Dig Dis Sci 2007;52:3435-3437.

19 Blaheta RA, Scholz M, Hailer NP, Bereiter-Hahn J, Encke A, Markus BH: Adhesion and penetration properties of human lymphocytes acting on allogeneic vascular endothelial cells. Immunology 1994;81:538-545.

20 Ronnblom LE, Alm GV, Oberg K: Autoimmune phenomena in patients with malignant carcinoid tumors during interferon-alpha treatment. Acta Oncol 1991;30:537-540.

21 Robert R, Fleisher T, Shearer W, Schroeder H, Frew A, Weyand C: Fundamental Principles of the Immune Response. Clinical Immunology Principles and Practice, 3rd ed. Elsevier, 2008, pp 3-26.

22 Gowda S, Tillman DK, Fitzpatrick JE, Gaspari AA, Goldenberg G: Imiquimod-induced vitiligo after treatment of nodular basal cell carcinoma. J Cutan Pathol 2009;36:878-881.

23 Sriprakash K, Godbolt A: Vitiligo-like depigmentation induced by imiquimod treatment of superficial basal cell carcinoma. Australas J Dermatol 2009;50:211-213.

24 Cerchione C, Fabbricini R, Pane F, Luciano L: Vitiligo-like lesions in an adult patient treated with imatinib mesylate. Leuk Res 2009;33:e104-e105.

25 Curzytek K, Pietowska J, Spiewak R: Vitiligo induced by drugs: a meta-analysis of reported cases. Allergy 2007;62(suppl 83:XXVI Congress of the European Academy of Allergology and Clinical Immunology):447.

26 Kovacs SO: Vitiligo. J Am Acad Dermatol 1998;38:647-666.

27 Schwartz RA, Janniger CK: Vitiligo. Cutis 1997;60:239-244.

28 MacKie RM: Vitiligo; in: Clinical Dermatology, 5th ed. Oxford University Press, New York, 2003, pp 227-229.

29 Svitra PP, Perry H: Vogt-Koyanagi-Harada (uveomeningitic) syndrome; in Albert DA, Jakobiec FA (eds): Principles and Practice of Ophthalmology: Clinical Practice v1. WB Saunders, Philadelphia, 1994, chapter 31.

30 Choudhuri G, Somani SK, Baba CS, Alexander G: Autoimmune hepatitis in India: profile of an uncommon disease. BMC Gastroenterol 2005;5:27.

31 Sarin SK, Monga R, Sandhu BS, Sharma BC, Sakhuja P, Malhotra V: Primary biliary cirrhosis in India. Hepatobiliary Pancreat Dis Int 2006;5:105-109.

32 Collin P, Reunala T: Recognition and management of the cutaneous manifestations of celiac disease: a guide for dermatologist. Am J Clin Dermatol 2003;4:13-20.

33 Amerio P, Di Rollo D, Carbone A, Auriemma M, Marra ME, De Remigis P, Feliciani C, Tracanna M, Tulli A Polyglandular autoimmune diseases in a dermatological clinical setting: vitiligo-associated autoimmune diseases. Eur J Dermatol 2010;20:354-358.

34 Tanioka M, Yamamoto Y, Katoh M, Takahashi K, Miyachi Y: Vitiligo vulgaris and autoimmune diseases in Japan: a report from vitiligo clinic in Kyoto University Hospital. Dermatoendocrinol 2009;1:43-45. 
35 Borlu M, Cölgeçen E, Evereklioglu C: Behçet's disease and vitiligo in two brothers: coincidence or association? Clin Exp Dermatol 2009;34:e653-e655.

36 Silva Dda F, Anunciação FA, Carvalho LL, Budaruiche JS: Vitiligo in a patient with pachydermoperiostosis: a fortuitous association? Acta Reumatol Port 2008;33:364-367.

37 Nanda A: Autoimmune diseases associated with neurofibromatosis type 1. Pediatr Dermatol 2008;25:392-393.

38 Sanli H, Akay BN, Arat M, Koçyigit P, Akan H, Beksac M, Ilhan O: Vitiligo after hematopoietic cell transplantation: six cases and review of the literature. Dermatology 2008;216:349-354.

39 Karabudak O, Dogan B, Yildirim S, Harmanyeri Y, Anadolu-Brasie R: Dermatitis herpetiformis and vitiligo. J Chin Med Assoc 2007;70:504-506.

40 Iacovelli P, Sinagra JL, Vidolin AP, Marenda S, Capitanio B, Leone G, Picardo M: Relevance of thyroiditis and of other autoimmune diseases in children with vitiligo. Dermatology 2005;210:26-30.

41 Kemp EH, Waterman EA, Weetman AP: Autoimmune aspects of vitiligo. Autoimmunity 2001;34:65-77.

42 Grimes PE: White patches and bruised souls: advances in the pathogenesis and treatment of vitiligo. J Am Acad Dermatol 2004;51:S5-S7.

43 Nouri K, Busso M, Machler BC: Vitiligo associated with alpha-interferon in a patient with chronic active hepatitis C. Cutis 1997;60:289-290. 